\title{
REPERCUSSÃO DA COMUNICAÇÃO SUPLEMENTAR E/OU ALTERNATIVA NA AFASIA NÃO FLUENTE
}

\author{
Augmentative and alternative communication repercussion \\ on non-fluent aphasia
}

\author{
Mariana Mendes Bahia ${ }^{(1)}$, Regina Yu Shon Chun (2)
}

\begin{abstract}
RESUMO
Objetivos: verificar as formas de comunicação e desempenho linguístico-cognitivo de afásicos a partir da Comunicação Suplementar e/ou Alternativa (CSA) e conhecer sua percepção. Métodos: pesquisa de abordagem qualitativa de corte longitudinal, aprovada pelo CEP, com amostra de 5 sujeitos afásicos não fluentes. A coleta de dados ocorreu por meio dos prontuários dos sujeitos, registros em vídeo do acompanhamento fonoaudiológico com a CSA e dos seus depoimentos acerca da utilização da CSA. Resultados: os sujeitos utilizam diversas formas de comunicação para se expressar além de fazerem maior uso da CSA, necessitando menor apoio de gestos próprios ao longo do estudo, o que facilitou a comunicação com o outro e diminuiu o uso de adivinhações e tentativas frustradas de conversas. O uso da CSA repercutiu no aumento da produção oral. Os sujeitos referem gostar de utilizar os recursos da CSA e que estes contribuem de alguma forma na sua comunicação. Conclusão: os resultados evidenciam que o apoio da CSA contribui para que os sujeitos estudados pudessem assumir seus lugares como falantes, superando suas dificuldades de linguagem. Deste modo, favoreceu que eles se colocassem como sujeitos linguísticos e sociais. As atividades dialógicas e contextualizadas, bem como a mediação do interlocutor, favoreceram o processo de (re)significação de seus enunciados. Portanto, a CSA, nesse contexto, mostra-se como importante recurso mediador e facilitador do processo linguístico nas afasias não fluentes com repercussão na produção oral.
\end{abstract}

DESCRITORES: Afasia; Auxiliares de Comunicação para Pessoas com Deficiência; Linguagem; Fonoaudiologia

\section{INTRODUÇÃO}

As chamadas Doenças Crônicas Não Transmissíveis (DCNT) são a principal causa de óbitos no mundo, sendo responsáveis por $63 \%$ das 57 milhões de mortes em 2008, segundo a Organização Mundial da Saúde - OMS ${ }^{1}$. Dessas mortes pelas DCNT, as causas cardiovasculares correspondem a 48\%, seguida de câncer

(1) Universidade Estadual de Campinas - UNICAMP, Campinas, São Paulo, Brasil.

(2) Curso de Graduação em Fonoaudiologia e do Mestrado Profissional Saúde, Interdisciplinaridade e Reabilitação da Universidade Estadual de Campinas - UNICAMP, Campinas, São Paulo, Brasil.

Fonte de auxílio: Fundação de Amparo à Pesquisa do Estado de São Paulo

Conflito de interesses: inexistente
(21\%) e doenças respiratórias crônicas $(12 \%)^{1}$. Acrescente-se ainda que mais de 9 milhões desses óbitos ocorreram em indivíduos com menos de 60 anos e poderiam ter sido prevenidos'.

No Brasil, nas últimas décadas, as DCNT passaram a liderar as causas de óbito no país², correspondendo a $74 \%$ das mortes, sendo as doenças cardiovasculares responsáveis por 33\% desse total'.

O Acidente Vascular Cerebral (AVC) faz parte das doenças cardiovasculares e representa, hoje, a segunda causa de morte no mundo e a primeira no Brasil $^{3-5}$, correspondendo a um grave problema de saúde pública ${ }^{6}$.

O AVC também é considerado a principal causa de incapacidade físico-funcional na vida adulta ${ }^{7}$. A dependência e a incapacidade para a realização de tarefas cotidianas ocorrem devido às diversas 
sequelas decorrentes do AVC, que vão depender do tipo, do local e da extensão da lesão, destacando-se as físicas, funcionais, emocionais e de comunicação.

Dentre as possíveis sequelas decorrentes de lesão cerebral por AVC, as alterações de linguagem são as que resultam em maior comprometimento funcional ${ }^{8}$. Estima-se que $58 \%$ das desordens de linguagem são causadas por AVC, e que parte das pessoas que tiveram AVC irá desenvolver alterações linguístico-cognitivas graves ${ }^{8}$.

Este estudo volta-se à afasia, alteração na compreensão e/ou produção da linguagem e processos afeitos a ela, cuja temática é aqui abordada pelas repercussões em diversos aspectos da vida dos sujeitos, pois além de afetar a linguagem, pode interferir nos processos relacionados, como a vida prática e as relações sociais e afetivas ${ }^{9}$, bem como as relações interativas e interpretativas como colocam diversos autores ${ }^{9,10}$.

Estima-se que $40 \%$ dos pacientes na fase aguda do AVC possuem afasia, sendo que metade deles irá permanecer com alguma alteração de linguagem na fase crônica ${ }^{11}$, necessitando de intervenção e reabilitação.

As afasias possuem classificação variável, sendo que aqui será enfocada a afasia não fluente, isto é, aquela cujos sujeitos apresentam uma fala entrecortada, com parafasias, prolongamentos, dificuldades de posicionamento e execução dos movimentos fonoarticulatórios ${ }^{12}$.

Dessa maneira, é importante considerar as construções linguísticas do discurso das pessoas com afasia bem como o contexto social, a interação e o modo como elas atuam com, sobre e na linguagem ${ }^{10,12,13}$. Portanto, no acompanhamento terapêutico (fonoaudiológico) das afasias é importante examinar as condições de produção discursiva, orais ou não orais, considerando diálogos e narrativas em uma perspectiva dialógica e contextualizada além de uma compreensão de sujeito social participante da (re)constituição de sua linguagem.

Como explicam alguns autores ${ }^{14}$, muitas vezes, os afásicos podem não apresentar progressos na situação de acompanhamento clínico ou que estes são insuficientes para evolução da linguagem. Nestes casos, a Comunicação Suplementar e/ou Alternativa (CSA) apresenta-se como uma possibilidade terapêutica ${ }^{13,15-17}$.

A CSA contribui como instrumento de mediação da linguagem que favorece ela própria, a (re)constituição dos sujeitos com alterações de linguagem e a qualidade de sua interação ${ }^{13}$. Pode ser entendida como uma abordagem clínico-educacional que: “(...) visa apoiar complementar, suplementar/melhorar, ou substituir as formas de produção e interpretação verbal de sujeitos não falantes ou com extremas dificuldades de linguagem"13 (p.2).

Alguns autores ${ }^{15,18,19}$ esclarecem que a CSA se compõe de um conjunto de diferentes componentes que pode auxiliar as pessoas com comprometimentos de linguagem, como nas afasias, a expressarem de maneira mais eficiente mensagens e necessidades (escritas e faladas). Desse modo, favorece a autonomia e a competência linguísticas bem como suas interações sociais.

Diante do exposto, interessa investigar a repercussão o uso da CSA no favorecimento da linguagem de sujeitos afásicos não fluentes. Os objetivos gerais são verificar as formas de comunicação e desempenho linguístico-cognitivo dos sujeitos a partir da implementação da CSA no acompanhamento fonoaudiológico e conhecer dos mesmos a percepção acerca dos recursos da CSA. Os objetivos específicos constituem: a) levantar formas de comunicação utilizadas antes e após implementação dos recursos de CSA; analisar o desempenho linguístico-cognitivo quanto aos aspectos de produção oral e escrita, uso de gestos próprios, compreensão e utilização dos recursos da CSA, necessidade de auxilio e mediação dos interlocutores após a implementação da CSA e c) levantar a percepção dos sujeitos quanto a comunicação e utilização dos recursos da CSA.

\section{MÉTODOS}

Este estudo foi aprovado pelo Comitê de Ética em Pesquisa da Universidade Estadual de Campinas sob no 124/2008.

Trata-se de pesquisa de abordagem qualitativa, corte longitudinal, cujo corpus se constitui de 05 sujeitos afásicos não fluentes, do Grupo II do Centro de Convivência de Afásicos e não Afásicos (CCA - IEL/UNICAMP) e participantes do acompanhamento fonoaudiológico em que se desenvolve o trabalho com a CSA. Os sujeitos (ou seus responsáveis) concordaram em participar livremente da pesquisa por meio da assinatura do Termo de Consentimento Livre e Esclarecido, de acordo com a Resolução 196/96 do CONEP. Os sujeitos foram selecionados em função do comprometimento da linguagem oral e interesse em utilizar a CSA.

A coleta de dados ocorreu por meio de três fontes:

a) prontuários institucionais para caracterização dos sujeitos relativa a breve histórico da afasia, condições linguístico-cognitivas e inicio de utilização dos recursos da CSA;

b) registros em vídeo do acompanhamento fonoaudiológico com a CSA para análise dos 
aspectos de linguagem dos sujeitos a partir do uso da CSA quanto às formas de comunicação utilizadas - linguagem oral e escrita, gestos próprios, expressão facial, e uso dos recursos da CSA, além da necessidade de auxilio e mediação dos interlocutores;

Os vídeos analisados compreenderam um período de 27 meses (03/2007 a 06/2009), totalizando 50 encontros. Desses, 19 foram selecionados para transcrição, conforme os objetivos da pesquisa.

c) depoimentos dos sujeitos acerca da comunicação e utilização da CSA. Para a coleta foi utilizada uma prancha de comunicação com símbolos do Sistema Pictográfico de Comunicação (SPC).

O acompanhamento fonoaudiológico com a CSA ocorreu em encontros semanais em grupo, com duração de 60 minutos cada, conduzidos pelas pesquisadoras com participação de voluntários, graduandos do Curso de Fonoaudiologia da UNICAMP. Foram construídas pranchas de comunicação individuais, específicas para cada sujeito, com símbolos do SPC, por ser este um sistema simbólico de fácil reconhecimento, com versão em português, além de ser mais utilizado em nosso país.

Ademais, foram desenvolvidas atividades contextualizadas de linguagem em uma perspectiva discursiva, de modo a atribuir sentidos às formas de produção dos sujeitos estudados, em que se buscou valorizar fatos e situações trazidas pelos participantes como resgate da sua história de vida pessoal, notícias de jornal, músicas, poesias, receitas culinárias, jogos e outras atividades de interesse do grupo $^{13}$. Durante as atividades foram oferecidos símbolos do SPC relacionados ao conteúdo trabalhado nos encontros.

Este estudo foi aprovado pelo Comitê de Ética em Pesquisa da instituição de origem sob $\mathrm{n}^{\circ}$ 124/2008.

A transcrição dos episódios selecionados seguiu o padrão adaptado do sistema de codificação do Banco de Dados em Neurolinguística ${ }^{20}$ em que os dados são apresentados por meio da numeração das linhas, sigla do locutor, transcrição ortográfica, observações sobre processos de significação verbais, observações sobre processos de significações não verbais, além de uma coluna adicional acerca das observações sobre processos de significação utilizando a CSA. As marcações da transcrição estão descritas na Figura 1:

Os depoimentos dos sujeitos foram norteados por meio das questões:

1) Como você faz para falar com as pessoas o que você quer?

\begin{tabular}{|c|c|}
\hline Marcação & Ocorrência \\
\hline$:$ & Alongamento \\
$I$ & Pausa breve \\
$I I$ & Pausa longa \\
- & Silabação \\
[ & Superposição de vozes \\
\hline
\end{tabular}

Figura 1 - Marcação da transcrição

2) Você acha que a prancha de comunicação e os símbolos podem ajudar (ou não) você a se comunicar com as outras pessoas?

3) Quais atividades você gostou de realizar com ajuda da prancha de comunicação e os símbolos?

\section{RESULTADOS}

Os resultados serão expostos em três itens: caracterização dos sujeitos, repercussões da CSA na linguagem e depoimentos acerca da utilização da CSA como ferramenta de comunicação.

\section{Breve caracterização dos sujeitos e utilização da CSA}

\section{Sujeito 1 (S1)}

59 anos, homem, divorciado, pedreiro. Teve quatro episódios de AVC em um período de 4 anos, apresentando como sequela afasia global e hemiplegia à direita. Possui comunicação oral restrita e fala com estereotipias verbais e gestuais, como por exemplo, "opa" e gesto de um círculo com as mãos, respectivamente. Segundo relatos da irmã, sua cuidadora, S1 não participa de festas familiares e demais eventos em que precisa se expor. Iniciou participação no grupo fonoaudiológico com a CSA em 05/2006, mostrando-se participativo e interessado no trabalho com a CSA, sobretudo em atividades que envolveram o resgate de sua história de vida.

\section{Sujeito 2 (S2)}

37 anos, mulher, solteira, empregada doméstica. Teve dois episódios de AVC em um período de 2 anos e meio, tendo como sequela afasia motora aferente, hemiparesia à direita e apraxia buco-facial, além de apresentar labilidade emocional. Apresenta expressão verbal reduzida e dificuldade de compreensão. Segundo relatos de seu irmão, S2 não gosta de frequentar locais públicos e apresenta crises de choro e riso. Apropriou-se rapidamente da CSA como forma de comunicação, não apresentando dificuldades no entendimento das propostas 
trabalhadas no grupo. Foi a participante que integrou o grupo mais tardiamente, em 06/2007.

\section{Sujeito 3 (S3)}

50 anos, mulher, solteira, terapeuta ocupacional. Teve ruptura de um aneurisma cerebral há mais de 20 anos, com comprometimento da artéria cerebral média à esquerda, tendo como sequela afasia motora eferente, disartria e hemiparesia à direita. Apresenta dificuldade de encadeamento do discurso, estereotipias verbais, como por exemplo, "preciso falar", "issau", "ai senhor" e "ótimo". Beneficia-se de promptings orais e visuais nas situações dialógicas, tem boa compreensão e se utiliza de diversos meios para ser entendida. Além disso, gosta de cantar, apresentando as estruturas melódicas das músicas preservadas. Iniciou 0 trabalho com a CSA em 05/2006, sendo bastante participativa e colaborativa nas atividades, ajuda os demais participantes em suas dificuldades.

\section{Sujeito 4 (S4)}

59 anos, mulher, casada, do lar. Sofreu um AVC há 6 anos, tendo como sequela afasia motora eferente com traços de afasia dinâmica e hemiparesia à direita de predomínio braquial. Apresenta falta de iniciativa verbal, sendo necessário que o interlocutor inicie o diálogo e o incentive, utiliza gestos com as mãos e a cabeça para transmitir a mensagem desejada e solicita ajuda do marido para fazer-se entender. Ingressou no grupo com a CSA em 05/2006 e demonstra entender a proposta de uso da CSA, utilizando-a nas atividades desenvolvidas sem apresentar dificuldades.

\section{Sujeito 5 (S5)}

67 anos, mulher, casada, professora aposentada. Teve um episódio de AVC hemorrágico desencadeado por uma crise de hipertensão há 11 anos, tendo como sequela afasia motora aferente, apraxia buco-facial e disartria. Possui fala entrecortada, com anomias, parafasias e prolongamentos com sincinesias da face, pescoço e tronco. Além disso, observa-se grande esforço ao falar, acompanhado de tensão na região cervical e da agudização da voz. Utiliza a escrita na comunicação. No trabalho com a CSA, iniciado em 05/2006, não apresentou dificuldades na compreensão e na utilização dos recursos. Por meio da CSA construía enunciados mais elaborados, nem sempre necessitando da mediação dos investigadores.

\section{Repercussões da CSA na linguagem}

Os dados extraídos dos registros em vídeo mostram que os sujeitos se utilizam de diversas formas de comunicação para expressar o conteúdo desejado, como uso dos símbolos do SPC, gestos próprios, expressão facial, produção oral, ainda que restrita em S1 e S2, e escrita, no caso de S5.

Verifica-se ao longo do período estudado, por meio da análise dos dados, que os sujeitos fizeram maior uso da CSA e necessitaram de menor apoio dos gestos próprios, o que facilitou a comunicação e interação com o outro, diminuindo as situações de adivinhação e tentativas frustradas de conversa. No caso de S2, S3 e S5 houve uso com facilidade dos recursos da CSA, bem como uso mais espontâneo da CSA para a comunicação, em alguns momentos.

S2, S3 e S4 se beneficiam do prompting visual e verbal para acessar a palavra desejada, uma vez que apresentam grande dificuldade de acesso lexical. S5 apresentou produções adequadas e mais elaboradas, se beneficiando das figuras e da escrita para chegar à palavra falada.

Observa-se que o maior uso da CSA repercutiu no aumento da produção oral dos sujeitos. No caso do sujeito S1, não houve um aumento significante da oralidade, no entanto, suas poucas oralizações foram muito importantes para o sujeito, devido suas condições físicas e de saúde após quatro episódios lesionais. Além disso, observa-se que S1 não apresentou as estereotipias verbais e gestuais descritas em relatórios fonoaudiológicos anteriores. Já com S2 observa-se aumento da oralização de vocábulos, demonstrando evolução do caso. S3 conseguiu produzir algumas frases simples, faladas com auxílio da figura e/ou da escrita dos símbolos da CSA. Houve diminuição das estereotipias verbais, que, apesar de soarem com entonação e o interlocutor compreender o que está querendo ser dito em alguns momentos, na maioria das vezes compromete o discurso. S4 produziu mais vocábulos, ao longo do tempo, sobretudo com apoio do prompting visual da CSA e verbal do interlocutor. Em S5 verifica-se maior uso dos símbolos ao longo do tempo juntamente com a produção oral, uma vez que os utiliza concomitantemente, além de maior produção oral de frases.

Os sujeitos demonstram entender as propostas apresentadas nas atividades terapêuticas, sendo que S3 e S5 não necessitam de ajuda para desenvolvê-las, ao contrário de $\mathrm{S} 1, \mathrm{~S} 2$ e $\mathrm{S} 4$, que precisaram da ajuda do outro em seu desenvolvimento. De maneira geral, os sujeitos sempre mantêm atenção nas atividades desenvolvidas no grupo, respeitam os tópicos discursivos e os mantém no diálogo, além de introduzirem novos tópicos conversacionais, sobretudo os sujeitos S3 e S5. S3 e S5 também ajudam os demais componentes do grupo nas propostas, incentivando-os, sendo que S3, muitas vezes, dá prompting verbal aos participantes do grupo. 
Ademais, observa-se diminuição das mediações feita pelos interlocutores. No entanto, cabe ressaltar que a mediação de sentidos feita pelo outro é necessária e importante para atribuição de significados às ações dos sujeitos, manutenção do jogo dialógico $e$, consequentemente, favorecimento da linguagem dos sujeitos. Para S1, a diminuição das mediações proporcionou/garantiu o tempo necessário para que ele complete seu enunciado, considerando-se seu tempo grande de latência de respostas. Para S5, a mediação do interlocutor se faz pouco necessária por apresentar grande potencial linguístico e, portanto, linguagem em funcionamento, sendo necessária quando apresenta dificuldade em reproduzir suas produções devido à apraxia.

As repercussões do uso da CSA na linguagem dos sujeitos são demonstradas por meio de alguns episódios mais relevantes, a título de ilustração, extraídos dos registros em vídeo.

\begin{tabular}{|c|c|c|c|c|c|}
\hline № & $\begin{array}{l}\text { Sigla } \\
\text { locutor }\end{array}$ & Transcrição & $\begin{array}{l}\text { Observação } \\
\text { processo de } \\
\text { significação } \\
\quad \text { verbais }\end{array}$ & $\begin{array}{c}\text { Observação } \\
\text { processo de } \\
\text { significação não } \\
\text { verbais }\end{array}$ & $\begin{array}{c}\text { Observação } \\
\text { processo de } \\
\text { significação CSA }\end{array}$ \\
\hline 1 & 11 & $\begin{array}{c}\text { Aqui seu S1 vamo } \\
\text { falá pra ela o que o } \\
\text { senhor já foi } \\
\text { também. Ela não } \\
\text { viu ainda. }\end{array}$ & Tom afirmativo & & $\begin{array}{l}\text { Coloca a prancha } \\
\text { com os símbolos } \\
\text { mais perto de } \mathrm{S} 1\end{array}$ \\
\hline 2 & S1 & & & & Olha os símbolos \\
\hline 3 & 11 & $\begin{array}{c}\text { Aponta pra ela } \\
\text { aqui. Que que é } \\
\text { que o senhor já foi? }\end{array}$ & Tom interrogativo & & $\begin{array}{c}\text { Mostra os símbolos } \\
\text { da categoria } \\
\text { pessoas }\end{array}$ \\
\hline 4 & S1 & & & & $\begin{array}{c}\text { Aponta o símbolo } \\
\text { de vigia }\end{array}$ \\
\hline 5 & 12 & Cadê o pedreiro? & Tom interrogativo & & \\
\hline 6 & 11 & $\begin{array}{c}\text { Esse é o vigia. O } \\
\text { senhor já foi vigia } \\
\text { também? }\end{array}$ & Tom interrogativo & & $\begin{array}{c}\text { Aponta o símbolo } \\
\text { de vigia }\end{array}$ \\
\hline 7 & S1 & O::pa! & Tom exclamativo & & \\
\hline 8 & 11 & $\mathrm{Ih!}$ & Tom exclamativo & & \\
\hline 9 & S1 & Hum! & Tom exclamativo & Sorri & \\
\hline 10 & 11 & E pedreiro? & Tom interrogativo & & $\begin{array}{l}\text { Aponta o símbolo } \\
\text { de pedreiro }\end{array}$ \\
\hline 11 & S1 & Oh:! & Tom exclamativo & & \\
\hline
\end{tabular}

Legenda: I1 e I2 - investigadores; S1 - sujeito 1

Figura 2 - S1: Episódio: fatos novos da vida (13 meses após a introdução da CSA)

No episódio transcrito na Figura 2, o uso da CSA possibilitou favorecimento da linguagem de S1, ainda que a produção oral tenha sido restrita (turnos $7,9,11$ ), o pouco que conseguiu produzir assume grande significado para suas condições. No dado acima, os integrantes do grupo estavam se apresentando para S2, recém chegada ao grupo. Todos sabiam que S1 tinha sido pedreiro, mas desconheciam que ele também já havia trabalhado como vigia. Por meio da CSA, S1 pode falar sobre coisas novas de sua vida (turno 4). 


\begin{tabular}{|c|c|c|c|c|c|}
\hline № & $\begin{array}{l}\text { Sigla } \\
\text { locutor }\end{array}$ & Transcrição & $\begin{array}{l}\text { Observação } \\
\text { processo de } \\
\text { significação } \\
\text { verbais }\end{array}$ & $\begin{array}{l}\text { Observação } \\
\text { processo de } \\
\text { significação } \\
\text { não verbais }\end{array}$ & $\begin{array}{c}\text { Observação } \\
\text { processo de } \\
\text { significação CSA }\end{array}$ \\
\hline 1 & 13 & E você? Seu nome & Tom reticente & & $\begin{array}{l}\text { Mostra os símbolos } \\
\text { com a pergunta }\end{array}$ \\
\hline 2 & $\mathrm{~S} 2$ & & & & $\begin{array}{c}\text { Olha na prancha } \\
\text { onde está escrito } \\
\text { seu nome }\end{array}$ \\
\hline 3 & $\mathrm{~S} 2$ & Cre-u-za. & Tom afirmativo & & \\
\hline 4 & 14 & Creuza. & Tom afirmativo & & \\
\hline 5 & 13 & $\begin{array}{c}\text { E você é:: O que } \\
\text { você faz? }\end{array}$ & Tom interrogativo & & $\begin{array}{c}\text { Mostra os símbolos } \\
\text { com a pergunta }\end{array}$ \\
\hline 6 & S2 & & & $\begin{array}{c}\text { Olha para I3 } \\
\text { mostrando que não } \\
\text { entendeu }\end{array}$ & \\
\hline 7 & 13 & $\begin{array}{l}\text { O que você faz? } \\
\text { Qual que é seu } \\
\text { trabalho? }\end{array}$ & Tom interrogativo & & \\
\hline 8 & S2 & & & $\begin{array}{c}\text { Faz gestos e } \\
\text { expressão de não }\end{array}$ & \\
\hline 9 & 13 & Não? & Tom interrogativo & & \\
\hline 10 & S2 & & & $\begin{array}{c}\text { Faz não com a } \\
\text { cabeça }\end{array}$ & \\
\hline 11 & 13 & $\begin{array}{c}\text { Não ta } \\
\text { trabalhando? }\end{array}$ & Tom interrogativo & & \\
\hline 12 & S2 & Não. & Tom afirmativo & $\begin{array}{c}\text { Faz não com a } \\
\text { cabeça }\end{array}$ & \\
\hline 13 & 12 & $\begin{array}{c}\text { Que que você } \\
\text { gosta de faze, CC? } \\
\text { Conta pra ela que } \\
\text { que você gosta de } \\
\text { faze / Vamos vira } \\
\text { aqui mais símbolos }\end{array}$ & Tom afirmativo & & Olhando a prancha \\
\hline 14 & 12 & $\begin{array}{l}\text { Que que você } \\
\text { gosta de faze? }\end{array}$ & Tom interrogativo & & $\begin{array}{c}\text { Vira as páginas da } \\
\text { prancha até a parte } \\
\text { dos verbos }\end{array}$ \\
\hline 15 & S2 & & & & $\begin{array}{c}\text { Aponta símbolo de } \\
\text { lavar a louça }\end{array}$ \\
\hline 16 & 12 & Olha já vai aponta. & Tom afirmativo & & \\
\hline 17 & S2 & & & & $\begin{array}{l}\text { Aponta símbolo de } \\
\text { fazer comida }\end{array}$ \\
\hline
\end{tabular}

Legenda: I2, I3 e I4 - investigadores; S2 - sujeito 2

\section{Figura 3 - S2: Apresentando o grupo para um visitante (22 meses após a introdução da CSA)}

S2 se apoderou do uso da CSA com facilidade desde sua introdução no grupo, utilizando-a de maneira espontânea, sobretudo nas situações em que apresenta maior dificuldade em oralizar (turnos 15 e 17). Além disso, S2 se utiliza de diferentes recursos para se comunicar (turnos 3 e 12, 6, 8 e 10,15 e 17) e beneficia-se da escrita e do desenho para acessar a palavra deseja, como ilustra os turno 2 e 3. A mediação do interlocutor é importante para a atribuição de sentido e significado, dando maior fluidez ao diálogo, além de usar a CSA nas perguntas facilitando a compreensão do sujeito (turno 1 e 5). 


\begin{tabular}{|c|c|c|c|c|c|}
\hline № & $\begin{array}{l}\text { Sigla } \\
\text { locutor }\end{array}$ & Transcrição & $\begin{array}{l}\text { Observação processo } \\
\text { de significação verbais }\end{array}$ & $\begin{array}{l}\text { Observação processo } \\
\text { de significação } \\
\text { não verbais }\end{array}$ & $\begin{array}{l}\text { Observação processo } \\
\text { de significação CSA }\end{array}$ \\
\hline 1 & 11 & $\begin{array}{l}\text { Vamos fazer uma com } \\
\text { os vizinhos da S3? }\end{array}$ & Tom interrogativo & Olha para S3 & $\begin{array}{c}\text { Aponta o símbolo de } \\
\text { vizinho }\end{array}$ \\
\hline 2 & S3 & & & & $\begin{array}{l}\text { Olha o símbolo de } \\
\text { vizinho }\end{array}$ \\
\hline 3 & 11 & $\begin{array}{c}\text { Tem vizinho lá na sua } \\
\text { casa? }\end{array}$ & Tom interrogativo & Olhando para S3 & \\
\hline 4 & S3 & Tem. & Tom afirmativo & $\begin{array}{c}\text { Balança a cabeça } \\
\text { afirmativamente }\end{array}$ & \\
\hline 5 & 11 & É? & Tom interrogativo & Olhando para S3 & \\
\hline 6 & 11 & $\begin{array}{l}\text { E ai? Eles deixam você } \\
\text { ale:gre, triste ou brava? }\end{array}$ & Tom interrogativo & & $\begin{array}{c}\text { Segura os símbolos de } \\
\text { alegre, triste e bravo e } \\
\text { mostra para S3 }\end{array}$ \\
\hline 7 & S3 & & & & $\begin{array}{l}\text { Pega da mão de I1 o } \\
\text { símbolo de alegre }\end{array}$ \\
\hline 8 & 11 & Alegre? & Tom interrogativo & Olhando para S3 & \\
\hline 9 & S3 & Ale:gre. & Tom afirmativo & Olhando para I1 & \\
\hline \multicolumn{6}{|c|}{ recorte } \\
\hline 10 & 11 & Então conta essa frase. & Tom afirmativo & & \\
\hline 11 & S3 & Issau: Oh issau: & Tom reticente & & $\begin{array}{l}\text { Aponta o símbolo com } \\
\text { sua foto e o de vizinho }\end{array}$ \\
\hline 12 & 11 & Vizi:nho. & Tom afirmativo & Olhando para S3 & \\
\hline 13 & S3 & $\begin{array}{c}\text { Oh:: ai oh.: / comer. } \\
\text { Hum::! }\end{array}$ & Tom exclamativo & & $\begin{array}{c}\text { Aponta símbolo de } \\
\text { comer }\end{array}$ \\
\hline 14 & 11 & Vai come. & Tom afirmativo & Faz sim com a cabeça & \\
\hline 15 & 15 & $\begin{array}{l}\text { Então vamos lá / S3, } \\
\text { né? Eu }\end{array}$ & Tom reticente & $\begin{array}{l}\text { Olhando para S3, } \\
\text { aponta para si } \\
\text { representando o eu }\end{array}$ & \\
\hline 16 & S3 & Eu. & Tom afirmativo & Olhando para 16 & \\
\hline 17 & 15 & Tomo. & Tom afirmativo & Olhando para S3 & \\
\hline 18 & S3 & Café: & Tom afirmativo & Olhando para I6 & \\
\hline 19 & 15 & Café: & Tom afirmativo & $\begin{array}{c}\text { Balança a cabeça } \\
\text { afirmativamente }\end{array}$ & \\
\hline 20 & S3 & Bolo. & Tom afirmativo & Olhando para I6 & \\
\hline 21 & 11 & Aonde? & Tom interrogativo & Olhando para S3 & \\
\hline 22 & S3 & Ė:: & Tom reticente & & $\begin{array}{c}\text { Aponta o símbolo de } \\
\text { vizinho }\end{array}$ \\
\hline 23 & 11 & Vi & $\begin{array}{c}\text { Tom reticente - dando } \\
\text { Prompting }\end{array}$ & Faz sim com a cabeça & \\
\hline 24 & S3 & $\mathrm{Zi}$ & & Olhando para I1 & $\begin{array}{l}\text { Apontando o símbolo de } \\
\text { vizinho }\end{array}$ \\
\hline 25 & 11 & $\mathrm{Zi}$ & $\begin{array}{c}\text { Tom reticente - dando } \\
\text { Prompting }\end{array}$ & Olhando para S3 & \\
\hline 26 & S3 & Vizinho. & Tom afirmativo & Olhando para I1 & $\begin{array}{l}\text { Apontando o símbolo de } \\
\text { vizinho }\end{array}$ \\
\hline 27 & 15 & l:sso! & Tom exclamativo & $\begin{array}{l}\text { Balança a cabeça } \\
\text { afirmativamente }\end{array}$ & \\
\hline 28 & S3 & Ai essa essau! & Tom exclamativo & $\begin{array}{c}\text { Aponta o dedo para sua } \\
\text { cabeça }\end{array}$ & \\
\hline \multicolumn{6}{|c|}{ recorte } \\
\hline
\end{tabular}

Legenda: I1 e I5 - investigadores; S3 - sujeito 3

Figura 4 - S3: Formando frases com os símbolos (10 meses após a introdução da CSA) 
Nesse episódio (Figura 4) verifica-se que S3 utiliza várias formas para comunicar o conteúdo desejado e, assim, manter a diálogo com seu interlocutor, sobretudo com o uso da produção oral, como ocorre nos turnos 4, 9, 13, 16, 18, 20 e 26, por exemplo, e uso da CSA (turnos 7, 11, 13, 22 e 24). Além disso, observa-se que $S 3$ se apóia na fala do interlocutor e nos símbolos para acessar o que deseja expressar por meio da produção oral (turnos 13, 22 a 26). No episódio ainda nota-se a presença de estereotipias verbais (turnos 11 e 28) produzidas por S3. Tais estereotipias soam ao interlocutor com entonações diversas e coerentes com o discurso, como se fossem substituições de palavras que S3 não conseguiu produzir devido à dificuldade de acesso lexical.

\begin{tabular}{|c|c|c|c|c|c|}
\hline № & $\begin{array}{l}\text { Sigla } \\
\text { locutor }\end{array}$ & Transcrição & $\begin{array}{l}\text { Observação processo } \\
\text { de significação verbais }\end{array}$ & $\begin{array}{l}\text { Observação processo } \\
\text { de significação } \\
\text { não verbais }\end{array}$ & $\begin{array}{c}\text { Observação processo } \\
\text { de significação CSA }\end{array}$ \\
\hline 1 & 11 & $\begin{array}{l}\text { Escolhe alguma coisa } \\
\text { pra comprá. }\end{array}$ & Tom afirmativo & & \\
\hline 2 & S4 & & & Olha para I1 & $\begin{array}{c}\text { Aponta o símbolo de } \\
\text { melancia }\end{array}$ \\
\hline 3 & 11 & Que que é esse aí? & Tom interrogativo & & \\
\hline 4 & S4 & Mancia. & Tom afirmativo & & \\
\hline 5 & 11 & Melan:cia. & Tom afirmativo & & \\
\hline 6 & S4 & Cia. & Tom afirmativo & & \\
\hline 7 & 11 & $\begin{array}{l}\text { Então vamo por uma } \\
\text { melancia aqui. }\end{array}$ & Tom afirmativo & & $\begin{array}{l}\text { Pega o símbolo de } \\
\text { melancia e coloca na } \\
\text { lista de compras }\end{array}$ \\
\hline 8 & 11 & $\begin{array}{l}\text { Que mais? Como se } \\
\text { fosse comprá lá pra } \\
\text { casa da senho:ra que o } \\
\text { pessoal lá gosta. }\end{array}$ & Tom afirmativo & & \\
\hline 9 & S4 & & & Olha para I1 & $\begin{array}{c}\text { Aponta o símbolo de } \\
\text { abacaxi }\end{array}$ \\
\hline 10 & 11 & Gosta & & & \\
\hline 11 & S4 & Bacaxi. & Tom afirmativo & & \\
\hline 12 & 11 & Abacaxi. & Tom afirmativo & & \\
\hline \multicolumn{6}{|c|}{ recorte } \\
\hline 13 & S4 & & & Chama I1 & $\begin{array}{l}\text { Mostra símbolo de } \\
\text { alface que colocou na } \\
\text { lista de compras }\end{array}$ \\
\hline 14 & 11 & Alface. & Tom afirmativo & & \\
\hline \multicolumn{6}{|c|}{ recorte } \\
\hline 15 & 11 & Pra bebe? & Tom interrogativo & & $\begin{array}{l}\text { Coloca os símbolos de } \\
\text { bebidas perto de S4 }\end{array}$ \\
\hline 16 & S4 & & & & $\begin{array}{c}\text { Pega o símbolo de suco } \\
\text { e coloca na lista de } \\
\text { compras }\end{array}$ \\
\hline 17 & 11 & Suco de caixi:nha. & Tom afirmativo & & \\
\hline 18 & S4 & & & & $\begin{array}{l}\text { Tira o símbolo de suco } \\
\text { da lista de compras }\end{array}$ \\
\hline 19 & S4 & & & & Pega o símbolo de leite \\
\hline 20 & 11 & Leite? & Tom interrogativo & & \\
\hline 21 & S4 & Sim. & Tom afirmativo & Faz sim com a cabeça & \\
\hline \multicolumn{6}{|c|}{ recorte } \\
\hline
\end{tabular}

Legenda: I1 - investigador; S4 - sujeito 4

Figura 5 - S4: Lista de compras (18 meses após a introdução da CSA) 
No dado transcrito acima se observa que S4 utiliza diversas vezes os símbolos da CSA (turnos $2,9,13,16,19)$, e estes servem de prompting para que ela acesse a palavra desejada e a produza oralmente, como ocorreu nos turnos 2 a 4 e 9 a 11. Importante considerar a participação da investigadora, que faz perguntas e atribui significados às ações de $\mathrm{S} 4$, construindo um diálogo e, assim, favorecendo a sua linguagem. $O$ sujeito mantém o tópico discursivo no turno 13 ao permanecer realizando sua lista de compras, mesmo sem a presença da investigadora, e sinaliza tal ação ao chamá-la para mostrar o novo item incluído na lista. Além disso, verifica-se que S4 se guia pela figura para significar o símbolo, fato este ilustrado pelos turnos 16 a 21.

\begin{tabular}{|c|c|c|c|c|c|}
\hline № & $\begin{array}{l}\text { Sigla } \\
\text { locutor }\end{array}$ & Transcrição & $\begin{array}{l}\text { Observação processo } \\
\text { de significação verbais }\end{array}$ & $\begin{array}{l}\text { Observação processo } \\
\text { de significação } \\
\text { não verbais }\end{array}$ & $\begin{array}{l}\text { Observação processo } \\
\text { de significação CSA }\end{array}$ \\
\hline 1 & 12 & $\begin{array}{c}\text { Então vamos lá. A dona } \\
\text { S5/ Pode continuar } \\
\text { a história da dona S5 } \\
\text { gente? Pode? }\end{array}$ & Tom interrogativo & & \\
\hline 2 & S3 & Pode. & Tom afirmativo & & \\
\hline 3 & 12 & Pode. Então vai lá. & Tom afirmativo & & \\
\hline 4 & S5 & $\begin{array}{l}\text { Cole, não, cunhada me } \\
\text { mé é Amélia, Lono:ra, a } \\
\text { Ci:// Ci: Cirinija, a. a:: a:: }\end{array}$ & Tom afirmativo & & $\begin{array}{l}\text { Aponta o símbolo de } \\
\text { cunhadas e segue com } \\
\text { o dedo o escrito com } \\
\text { o nome delas (Amélia, } \\
\text { Eleonora e Leonilda) }\end{array}$ \\
\hline 5 & 16 & & & $\begin{array}{c}\text { Articula o nome que S5 } \\
\text { está tentando ler sem } \\
\text { emitir som }\end{array}$ & \\
\hline 6 & S5 & $A::$ & Tom afirmativo & & \\
\hline 7 & 16 & $\mathrm{Eu}$ & $\begin{array}{c}\text { Tom afirmativo - dando o } \\
\text { prompting }\end{array}$ & & \\
\hline 8 & S5 & Eunice, Aparecida. & Tom afirmativo & & $\begin{array}{l}\text { Segue com o dedo o } \\
\text { escrito com o nome das } \\
\text { cunhadas (Eunice e } \\
\text { Aparecida) }\end{array}$ \\
\hline 9 & 12 & São quatro cunhada? & Tom interrogativo & & \\
\hline 10 & 16 & & & Faz cinco com os dedos & \\
\hline 11 & 12 & Cinco cunhadas? & Tom interrogativo & & \\
\hline 12 & S5 & É é. & Tom afirmativo & & \\
\hline 13 & 12 & Que mais? & Tom interrogativo & & \\
\hline 14 & S5 & É:// a meu imão é doise. & Tom afirmativo & & $\begin{array}{c}\text { Aponta o símbolo de dois } \\
\text { e de irmãos }\end{array}$ \\
\hline 15 & 12 & Dois irmãos. & Tom afirmativo & & \\
\hline 16 & S5 & A::/ a::/ a Jaquim:// não. & Tom negativo & & $\begin{array}{c}\text { Segue com o dedo o } \\
\text { nome dos irmãos escrito } \\
\text { no papel }\end{array}$ \\
\hline 17 & 12 & $\begin{array}{c}\text { É ao contrário, né? Que } \\
\text { tá escrito aí? Quem é } \\
\text { que tá primeiro? }\end{array}$ & Tom interrogativo & & \\
\hline 18 & S5 & A/ a João e a Jaquim. & Tom afirmativo & & $\begin{array}{c}\text { Segue com o dedo o } \\
\text { nome dos irmãos escrito } \\
\text { no papel }\end{array}$ \\
\hline 18 & 12 & Joaquim. & Tom afirmativo & & \\
\hline 20 & S5 & O mora Mato Gosso. & Tom afirmativo & & \\
\hline 21 & 12 & $\begin{array}{c}\text { Quem que mora no Mato } \\
\text { Grosso? O João ou o } \\
\text { Joaquim? }\end{array}$ & Tom interrogativo & & \\
\hline 22 & S5 & Não. É:: & Tom afirmativo & Faz dois com os dedos & \\
\hline 23 & 12 & Os dois? & Tom interrogativo & & \\
\hline 24 & S5 & É é é! & Tom exclamativo & Faz sim com a cabeça & \\
\hline
\end{tabular}




\begin{tabular}{|c|c|c|c|c|c|}
\hline 25 & 12 & $\begin{array}{l}\text { Ah! Os dois moram no } \\
\text { Mato Grosso. }\end{array}$ & Tom exclamativo & & \\
\hline 26 & S5 & É can Canto Gi Gande. & Tom afirmativo & & \\
\hline 27 & 12 & Campo Grande? & Tom interrogativo & & \\
\hline 28 & S5 & É. & Tom afirmativo & & \\
\hline 29 & 12 & Ah::! & Tom exclamativo & $\begin{array}{c}\text { Faz sim com a cabeça } \\
\text { e sorri }\end{array}$ & \\
\hline 30 & S5 & É/ a Jaquim mora// é:: & Tom reticente & & \\
\hline 31 & 12 & O Joaquim mora:: & Tom reticente & & \\
\hline 32 & S5 & $\dot{E}:: / /$ & Tom reticente & & Procura na agenda \\
\hline 33 & 12 & Cadê sua cola? & Tom interrogativo & ri & \\
\hline 34 & S5 & É:: é:: & Tom reticente & & \\
\hline 35 & 12 & Cuiabá? & Tom interrogativo & & \\
\hline 36 & S5 & NÃO! & Tom exclamativo & Faz não com a cabeça & \\
\hline 37 & 12 & $\begin{array}{l}\text { È em Campo Grande } \\
\text { também? }\end{array}$ & Tom interrogativo & & \\
\hline 38 & S5 & NÃO! & Tom exclamativo & & \\
\hline 39 & 12 & $\begin{array}{l}\text { Lá perto de (fala } \\
\text { ininteligível) }\end{array}$ & Tom interrogativo & & \\
\hline 40 & S5 & $\begin{array}{c}\text { A: Mato/ não// Javieiro } \\
\text { do Sul. }\end{array}$ & Tom afirmativo & & \\
\hline 41 & 12 & $\begin{array}{l}\text { Alguma coisa do Sul, né } \\
\text { que a senhora falou? }\end{array}$ & Tom interrogativo & & \\
\hline 42 & S5 & É. & Tom afirmativo & $\begin{array}{c}\text { Pega uma folha de papel } \\
\text { e escreve Fátima }\end{array}$ & \\
\hline 43 & 16 & Fá:tima! & Tom exclamativo & Le o que S5 escreveu & \\
\hline 44 & 12 & Ah:: Fátima do Sul! & Tom exclamativo & & \\
\hline 45 & S5 & È é. & Tom afirmativo & Faz sim com a cabeça & \\
\hline 46 & 12 & É lá perto de Cuiabá:? & Tom interrogativo & & \\
\hline 47 & S5 & É// não! & Tom exclamativo & & \\
\hline 48 & 12 & Não, de Campo Grande! & Tom exclamativo & $\mathrm{Ri}$ & \\
\hline 49 & S5 & É! & Tom exclamativo & $\mathrm{Ri}$ & \\
\hline 50 & 16 & & & $\mathrm{Ri}$ & \\
\hline 51 & S3 & Essa essau! & Tom exclamativo & & \\
\hline 52 & 12 & Ela sabe tudo, né S3? & Tom interrogativo & & \\
\hline 53 & S5 & É:: & Tom afirmativo & & \\
\hline 54 & S3 & Oh é! & Tom exclamativo & & \\
\hline 55 & S5 & $\begin{array}{c}\text { É:/ a a do foi a passeá } \\
\text { dua veisse }\end{array}$ & Tom reticente & Faz dois com os dedos & \\
\hline 56 & 12 & $\begin{array}{c}\text { A senhora foi passear lá } \\
\text { duas vezes? }\end{array}$ & Tom interrogativo & & \\
\hline 57 & S5 & $\begin{array}{l}\text { Não. A: a ondimo. } \\
\text { O-ni-mo. }\end{array}$ & Tom afirmativo & $\begin{array}{c}\text { Pega o lápis para } \\
\text { escrever }\end{array}$ & \\
\hline 58 & 16 & Ônibus? & Tom interrogativo & & \\
\hline 59 & S5 & É. & Tom afirmativo & $\begin{array}{c}\text { Olha para I6 e faz sim } \\
\text { com a cabeça }\end{array}$ & \\
\hline 60 & 16 & Ônibus. Foi de ônibus? & Tom interrogativo & & \\
\hline 61 & S5 & É! A: a sozinha. & Tom afirmativo & & \\
\hline recorte & & & & & \\
\hline
\end{tabular}

Legenda: I1 e I3 - investigadores; S5 - sujeito 5

Figura 6 - S5: Conversando sobre a família (34 meses após a introdução da CSA) 
O episódio transcrito mostra que S5 não apresenta dificuldade na compreensão nem na utilização da CSA para se comunicar. Verifica-se que S5 se utiliza de vários processos de significação como uso dos símbolos e da escrita para acessar o que deseja falar (turnos 4, 8, 14, 16 e 18). Com a CSA, S5 pode contar sobre sua família bem como das atividades de sua vida cotidiana neste episódio. Iniciou novos tópicos de conversação a partir da atividade proposta, como contar onde os irmãos moram (turnos 20, 26, 40 e 42), sobre tê-los visitado (turno 52) e ter viajado de ônibus (turnos 57 e 61).

Ademais, S5 utiliza a prancha de CSA em conversação de maneira espontânea, mas dá preferência à tentativa de produção oral, como se observa neste episódio. Além disso, pode-se verificar que S5 constrói enunciados orais, porém algumas de suas produções são prejudicadas por dificuldades práxicas (turnos 4, 16, 26, 40, 55 e 57).

\section{Depoimentos acerca da utilização da CSA}

Os depoimentos dos sujeitos referentes à linguagem e ao uso da CSA mostram que ainda possuem dificuldade de se comunicar com o outro e expressar o conteúdo desejado, o que fica evidenciado pelas respostas como usar gestos (S2 e S3), apontar (S1) e as pessoas tentarem adivinhar (S1, S2, S3, S4), quando questionados acerca de como fazem para falar com as pessoas. Ainda apareceu como respostas o uso da CSA (S1 e S5), tentar falar (S1, S3 e S5) e escrever (S5). A Figura 7 ilustra a resposta dada por $\mathrm{S} 1$.
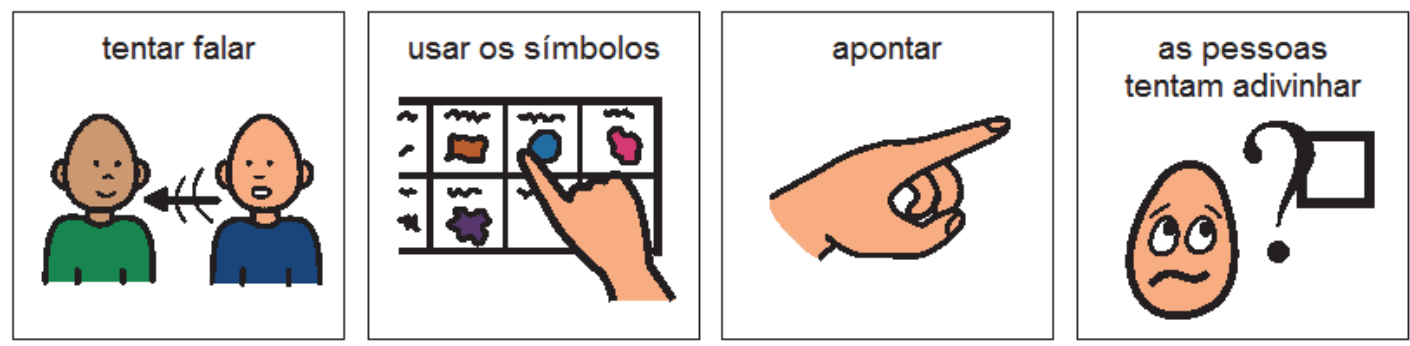

Figura 7 - Resposta de S1 sobre sua forma de comunicação com as pessoas

Os sujeitos ainda referem que gostam de usar a prancha de comunicação e os recursos da CSA e que estes contribuem um pouco (S1 e S2) ou muito (S3, S4 e S5) na comunicação deles com as demais pessoas. Alguns precisam de ajuda mais do que outros, como referido por S2, e outros, como S1 e S2, acham sua utilização difícil. A Figura 8 ilustra o que S5 acha acerca da utilização da CSA para a comunicação.
Os depoimentos também evidenciam que a CSA tem contribuído para favorecer a conversar entre os sujeitos do grupo e entre eles e as demais pessoas, além do desenvolvimento de atividades como jogos (S1 e S5), construção de poesias (S1) e de cartões (S1, S2, S3, S4 e S5) e de atividades de interesse dos participantes como cantar (S2 e S3) e trocar receitas (S3, S4 e S5). A Figura 9 evidencia as atividades que $\mathrm{S} 3$ gostou de realizar com auxilio da CSA.

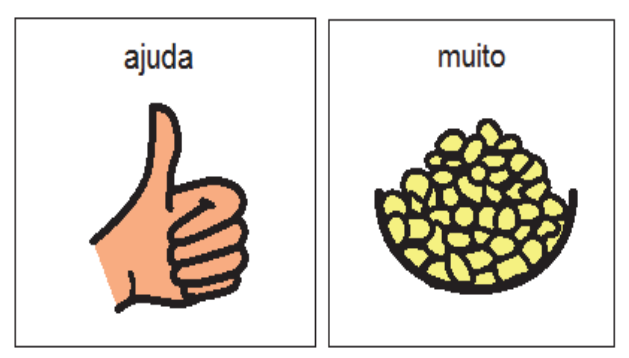

Figura 8 - Resposta de S5 sobre a utilização da prancha e dos símbolos de CSA para a comunicação 


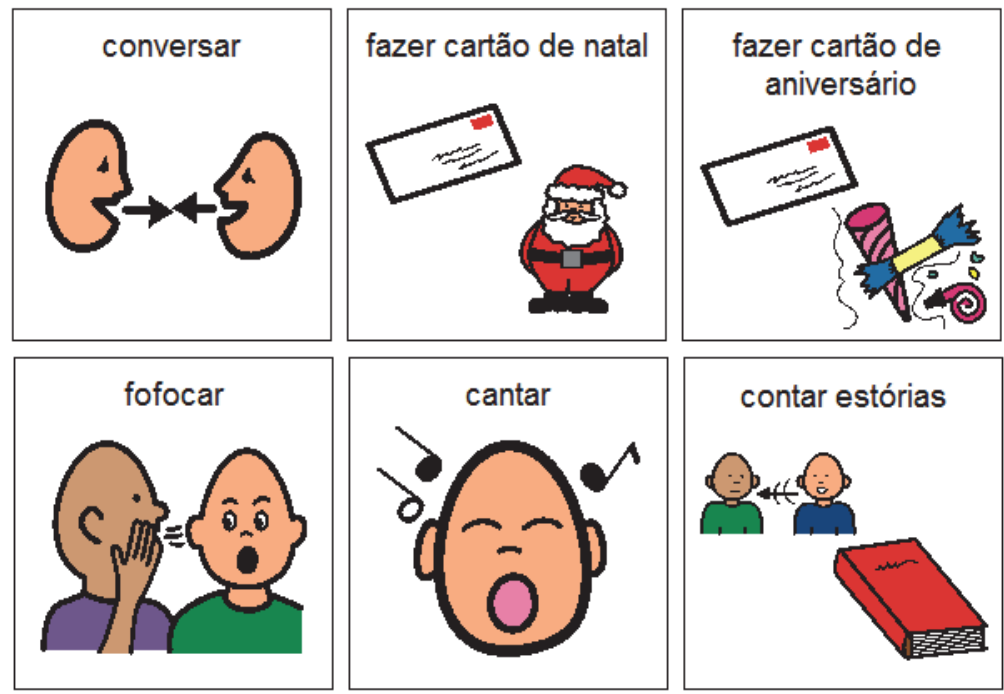

Figura 9 - Resposta de S3 sobre as atividades que mais gostou de realizar com ajuda da CSA

\section{DISCUSSÃO}

Alguns autores ${ }^{21,22}$ discutem acerca do uso da CSA na afasia, em qual momento iniciar a intervenção e qual o tipo de afásico que pode se beneficiar dessa abordagem, concluindo que todas as pessoas com afasia podem obter ganhos com o uso da CSA independente do tipo e do grau de comprometimento, o que corrobora com os achados encontrados, uma vez que todos os sujeitos do estudo, de algum modo, se beneficiaram dos recursos da CSA, mesmo que em medidas diferentes, como mostra a análise dos episódios transcritos.

Ademais, alguns autores ${ }^{21-23}$ colocam que quando sujeitos afásicos ficam impossibilitados de produzir uma linguagem funcional, que não satisfaça suas necessidades de comunicação por meio da fala é importante que se utilizem de outras estratégias, como a CSA, que abrange desenho, gestos estruturados ou não e a escrita, como fica evidenciado nos resultados.

Os episódios transcritos mostram que os sujeitos se utilizam de diversas formas de comunicação para expressar o conteúdo desejado, como uso da CSA, gestos próprios, expressão facial, produção oral, ainda que restrita nos casos dos sujeitos $\mathrm{S} 1 \mathrm{e}$ S2, e escrita, no caso de S5. Verifica-se ao longo do período estudado, por meio da análise dos dados, que os sujeitos fizeram maior uso da CSA e necessitaram de menor apoio de gestos próprios, o que facilitou a comunicação com o outro, evitando adivinhações e tentativas frustradas de conversas. Tais achados também foram encontrados por outros autores $^{13,17}$, em que se coloca a possibilidade de utilização de diversas modalidades de linguagem no trabalho com afásicos, sendo que os recursos da CSA possibilitam o acesso a outras formas de comunicação, como a linguagem oral.

Alguns estudos ${ }^{13,17,24}$ pontuam que o uso da CSA não inibe a fala e pode favorecer a linguagem oral, tendo em vista que a utilização de recursos facilitadores da comunicação permite o sujeito se fazer entender nas diversas situações cotidianas, o que favorece sua expressividade.

Os resultados mostram que o apoio da CSA contribui para o sujeito possa assumir seu lugar como falante ${ }^{13,17}$. Nesse sentido, alguns autores ${ }^{12,13}$ ressalvam que, em que pesem as dificuldades linguístico-cognitivas, devido à lesão cerebral, os afásicos mantém o estatuto de sujeitos sociais e, portanto, da linguagem.

A análise dos aspectos linguísticos-cognitivos dos sujeitos estudados demonstra, portanto, a importância do papel do outro, sejam os investigadores, sejam os próprios sujeitos, nas atividades discursivas quanto à atribuição de sentidos e interpretação verbal de modo a superar as dificuldades linguísticas próprias da afasia como demonstram os trabalhos que seguem a Neurolinguística Discursiva ${ }^{10,13,16}$.

O trabalho com a CSA, de maneira geral, possibilitou maior participação dos sujeitos do grupo nas atividades desenvolvidas, o que contribuiu para favorecer suas produções linguísticas e a interação social, resultados apontados em outros estudos ${ }^{13,23}$, que mostram que a CSA favorece os aspectos linguístico-cognitivos e psíquicos, contribuindo para maior independência na comunicação e participação nas atividades de vida. 


\section{CONCLUSÃO}

Os resultados da repercussão da CSA na linguagem de sujeitos afásicos aqui encontrados, em uma perspectiva discursiva de linguagem, fornecem subsídios para maior compreensão dessa temática na clínica fonoaudiológica.

Observa-se que as dificuldades linguísticas dos sujeitos estudados não os impediram de se colocarem como sujeitos da/na linguagem, sendo que as atividades dialógicas e contextualizadas, bem como a mediação do interlocutor, contribuíram no processo de mediação e de (re)significação de seus enunciados. A CSA, nesse contexto, se evidencia como facilitadora da produção discursiva e da oralidade desses sujeitos.

O uso da CSA pode ampliar as possibilidades linguísticas das pessoas com afasia e promover mudanças na interação social e nas relações sociais, favorecendo uma participação mais ativa dos sujeitos.

A utilização da CSA favoreceu as produções discursivas e dialógicas na situação de acompanhamento clínico e na vida cotidiana dos sujeitos afásicos, mostrando-se como um importante mediador do processo linguístico nas afasias, tendo em vista uma perspectiva de atenção integral, de promoção da saúde e de qualidade de vida desses sujeitos e de seus familiares.

\section{AGRADECIMENTOS}

Agradecemos à Fundação de Amparo a Pesquisa do Estado de São Paulo pelo auxílio recebido (Processo no 2008/01782-4) e aos sujeitos da pesquisa pela participação no estudo.

\begin{abstract}
Purpose: verify the communication forms and linguistic-cognitive performance of aphasics from an Augmentative and Alternative Communication (AAC) perspective and to evaluate their perception. Methods: this is a longitudinal research with qualitative approach, approved by the Ethic and Research Committee. The sample includes 5 non-fluent subjects with aphasia. Data was collected analyzing the subjects' files, video records of speech and language therapy focused on AAC, and the subjects opinions about it. Results: subjects used several ways of communication to express themselves as well as increased their use of AAC. In doing so, they demanded less gestures support during the study, which facilitated their communication and diminished guessing and frustrated conversation attempts. The use of AAC resulted in the increase of oral production. Subjects referred that they enjoyed using AAC and that it contributed to their communication in some way. Conclusion: results showed that AAC support contributed to subjects so they could assume their position as speakers, overcoming their language difficulties. Therefore it has facilitated them to assume themselves as linguistic and social subjects. Dialogic and contextualized activities, as well as the interlocutor mediation, facilitated the process of (re)signification of their enunciations. Therefore, regarding this context, AAC is an important support that mediates and facilitates the linguistic process on non-fluent aphasias with repercussions on oral production.
\end{abstract}

KEYWORDS: Aphasia; Communication Aids for Disabled; Language; Speech, Language and Hearing Sciences

\section{REFERÊNCIAS}

1. World Health Organization. Noncommunicable diseases - Country profiles 2011. Geneva: WHO; 2011. 207p.

2. Brasil. Ministério da Saúde. A vigilância, o controle e a prevenção das doenças crônicas não transmissíveis: DCNT no contexto do Sistema
Único de Saúde brasileiro. Brasília: OPAS/OMS; 2005. 80p.

3. Strong K, Mathers C, Bonita R. Preventing stroke: saving lives around the world. Lancet Neurol. 2007;6:182-7.

4. Lotufo P. Stroke in Brazil: a neglected disease. São Paulo Med J. 2005;123:3-4.

5. Brasil. Ministério da Saúde - Secretaria de Vigilância em Saúde. Saúde Brasil 2007 - Uma 
análise da Situação de saúde: perfil de mortalidade do brasileiro. Brasília: Ministério da Saúde; 2008. 50p.

6. Feigin V. Stroke in developing countries: can the epidemic be stopped and outcomes improved? Neurology. 2007;6:94-7.

7. Fernandes PT, Avelar WM, Mory SB, Hansen R, Li LM. Perception and attitudes towards stroke by professionals of emergnecy medical service in an urban city in southeastern Brazil. J Stroke Cerebrovasc Dis. 2009;18:195-7.

8. Mansur LL, Radanovic M, Rüegg D, Mendonça LIZ de, Scaff M. Descriptive study of 192 adults with speech and language disturbances. São Paulo Med J/Rev Paul Med. 2002;120:170-4.

9. Morato EM (org), Tubero AL, Santana AP, Damasceno B, Souza FF de, Macedo H de O et al. Sobre as afasias e os afásicos: subsídios teóricos e práticos elaborados pelo Centro de Convivência de Afásicos (Universidade Estadual de Campinas). Campinas: Editora Unicamp, 2002.

10. Coudry MHI. Diário de Narciso: discurso e afasia: análise discursiva de interlocuções com afásicos. $3^{\text {a }}$ ed. São Paulo: Martins Fontes, 1986/2001.

11. Bakheit AMO. The rate and extent of improvement with therapy from the different types of aphasia in the first year after stroke. Clin Rehabil. 2007;21:941-9.

12. Fedosse E. Acompanhamento fonoaudiológico de um sujeito afásico não-fluente: foco na continuidade sensório-motora. Disturb Comum. 2007;19(3):403-14.

13. Chun RYS. Processo de significação de afásicos usuários de comunicação suplementar e/ou alternativa. Rev Soc Bras Fonoaudiol. 2010;15(4):598-603.

14. Couto EAB. Utilização dos sistemas aumentativos e alternativos de comunicação na reabilitação das afasias. In: Almirall CB, Soro-Camats E, Bulto CR. Sistemas de sinais e ajudas técnicas para a comunicação alternativa e a escrita. São Paulo: Livraria Santos Editora, 2003, p. 231-41.
15. Lasker JP, Garrett KL. Aphasia and AAC: Enhancing communication across health care ettings. The ASHA Leader. 2008;13(8):10-3.

16. Chun RYS, Fedosse $\mathrm{E}$, Coudry $\mathrm{MIH}$. Comunicação Suplementar e/ou Alternativa: avaliação e acompanhamento fonoaudiológico de sujeitos não falantes. Diretrizes, Normas e Condutas - Área de Saúde FCM/UNICAMP. 2007. Disponível em: <www.fcm.unicamp.br> Último acesso: 09 de janeiro de 2012.

17. Galli JFM, Oliveira JP de, Deliberato D. Instrodução da comunicação suplementar e alternativa na terapia com afásicos. Rer Soc Bras Fonoaudiol. 2009; 14(3):402-19.

18. Hodge S. Why is the potential of augmentative and alternative communication not being realized? Exploring the experiences of people who use communication aids. Disability \& Society. 2007;22(5):457-71.

19. Cameron D, Markowicz L. Augmentative and alternativecommunication: International perspective. Occupational Therapy Now. 2009;11(1):12-4.

20. Coudry $\mathrm{MIH}$. Projeto Integrado em Neurolinguística: avaliação e banco de dados, 2006. CNPq: 521773/95-4 (impresso).

21. Beukelman DR, Fager S, Ball L, Dietz A. AAC for adults with acquired neurological conditions: a review. Augment Altern Commun. 2007;23(3):230-42.

22. Beukelman DR, Ball JR, Fager S. An AAC personnel framework: adults with acquired complex communication needs. Augment Altern Commun. 2008;24(3):255-67.

23. Johnson RK, Hough MS, King CA, Vas P, Jeffs T. Functional Communication in Individuals with Chronic Severe Aphasia Using Augmentative Communication. Augment Altern Coomun. 2008;24(4):269-80.

24. Chun RYS. Comunicação Suplementar e/ou Alternativa: favorecimento da linguagem de um sujeito não falante. Pró-Fono Rev Atual Cient. 2003;15(1):55-64.

http://dx.doi.org/10.1590/1982-021620146612

Recebido em: 30/03/2012

Aceito em: 29/10/2012

Endereço para correspondência:

Mariana Mendes Bahia

Rua Conselheiro Paula Sousa, 707

Campinas - SP

CEP: $13083-080$

E-mail: mariana_mbahia@yahoo.com.br 